\title{
Potato in the age of biotechnology
}

\section{Ewen Mullins ${ }^{1}$, Dan Milbourne ${ }^{1}$, Carlo Petti ${ }^{1}$, Barbara M. Doyle-Prestwich ${ }^{2}$ and Conor Meade ${ }^{3}$}

${ }^{1}$ Plant Biotechnology Unit, Teagasc Crops Research Centre, Oakpark, Carlow, Ireland

${ }^{2}$ Department of Zoology, Ecology and Plant Science, National University of Ireland Cork, Ireland

${ }^{3}$ Institute of Agroecology and Bioengineering, National University of Ireland, Maynooth, Ireland

\begin{abstract}
Biotechnology-based tools are now widely used to enhance and expand the traditional remit of potato in food production. By modifying its functionality, the capacity of the potato to produce, for example, therapeutic or industrial compounds is now a reality, and its ability to resist disease can also be radically improved. Two developments have been crucial to expanding the role of potato: the recent advances in the fields of structural and functional potato genomics and the ability to integrate genes of interest into the potato genome. In this review we discuss how both developments have diversified the remit of this crop.
\end{abstract}

\section{Potato production}

In Europe in the $1700 \mathrm{~s}$ it was believed that the consumption of potatoes led to leprosy, cholera, rickets and tuberculosis [1]. Today, potatoes are grown in $\sim 125$ countries and more than a billion people worldwide consume them on a daily basis. To support this demand, a multitude of varieties have been developed to resist preor post-harvest diseases, to target specific markets that require post-harvest processing (e.g. chipping) or to meet the nutritional requirements at the community level. As well as providing starch, potatoes are rich in vitamin C, have high levels of potassium and are an excellent source of fibre. Potato is an easy-to-grow plant and can provide more nutritious food faster and on less land than any other food crop, and in almost any habitat.

Since the 1960s, global potato production has remained relatively static ( 285.4 million tonnes \pm 0.19 million tonnes) [2]. However, this does not reflect the dramatic rate of increase in production across India, China and the African continent, which have witnessed a nine-, five- and sixfold increase in potato production, respectively [2] (Figure 1). This is in contrast to a modest 1.6-fold increase across North America (USA and Canada) and a 54\% decrease in production across the European Union (pre-2004 expansion of member states) over the same period [2]. A shift towards the use of potato in convenience foods (e.g. potato chips and fries) has been recorded in developed nations, but in developing economies the majority of the potato crop is still used for direct consumption [2]. Overall, potato is likely to maintain, if not increase, its relative economic importance in the decades ahead. As potato exerts a major socio-

Corresponding author: Mullins, E. (emullins@oakpark.teagasc.ie).

Available online 18 April 2006 economic influence on society today, countries that wish to remain competitive in the emerging global potato market must accelerate their development of yield-increasing technology (http://www.cipotato.org/market/potatofacts/ growprod.htm) and find ways of creating novel markets.

\section{Genomics-based research initiatives}

The emergence of molecular marker-based genetic mapping in the mid-1980s represented an exciting step forward in the ability to characterize the genomes of higher animals and plants. To date, molecular markerbased maps of potato have facilitated the identification of genetic loci underlying many important agronomic traits in potato. These include at least 19 major disease resistance genes and numerous quantitative trait loci (QTLs) for disease resistance (reviewed in [3]), morphological, developmental and quality traits. These studies have served to confirm the long-standing hypothesis that many of the most important agronomic traits in potato (e.g. yield and dry matter content) are under the control of multiple genes, which exhibit a complex set of interactions with both each other and the environment.

Gaining a complete understanding of the genetics of such complex traits is central to our ability to use biotechnology for the improvement of potato. Fuelled by technological developments in the analysis of the human genome, several high-throughput genomics programmes have been established for potato (and many other plant species). The ultimate goal of these initiatives is to establish the identity and action of every gene in the potato genome. In the USA, the National Science Foundation (NSF) Potato Genome project (http://www. potatogenome.org) has enabled the sequencing of 130000 expressed sequence tags (ESTs) from seven potato cDNA libraries (five core and two pathogen challenged), which has facilitated the production of a publicly available $10000 \mathrm{cDNA}$ micro-array (http://www.tigr.org/tdb/potato/ SGED_index2.shtml). The Canadian Potato Genome Project (CPGP, http://www.cpgp.ca) has similar goals: (i) to produce high-quality cDNA libraries for at least 100000 EST sequences from multiple libraries; (ii) to generate a micro-array consisting of at least 10000 non-redundant genes; and (iii) to produce a large population of activationtagged mutant plants for trait screening. Novel approaches, such as activation tagging $[4,5]$ and virusinduced gene silencing (VIGS) [6], are essential tools for a heterozygous outbreeding autotetraploid such as potato for which the development of traditional knockout 


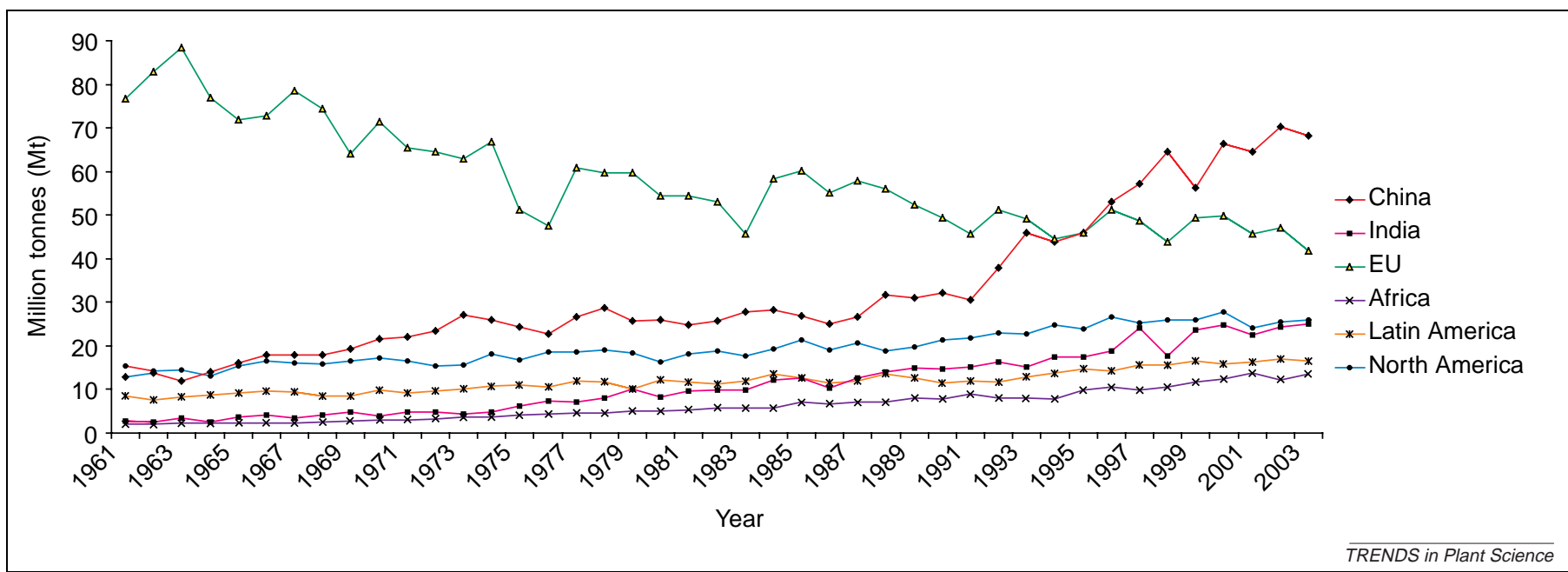

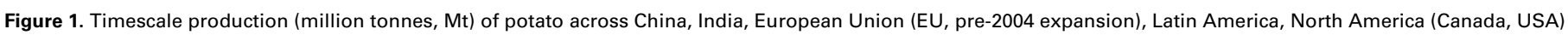
and the African continent between 1961 and 2003 (data collated from Food and Agricultural Organization of the United Nations Statistical Database [2]).

mutants using chemical and/or radioactive mutagenesis is not feasible.

Similar potato genomics programmes are underway in Europe, funded by both EU Framework Programmes and individual national bodies. Under the auspices of The Netherlands Genomics Initiative, the Centre for Biosystems Genomics (http://www.cbsg.nl/) has been tasked with unravelling the genetic networks associated with multi-factorial traits in potato (along with tomato and Arabidopsis). The programme comprises nine projects and covers various aspects of disease resistance, tuber quality and genetic variation. The GABI-CONQUEST programme in Germany is a similar initiative that has focused primarily on the candidate gene approach for the dissection of complex traits (http://www.gabi.de/21seiten/a_00_e. php). More recently, an international Potato Genomics Sequencing Consortium (http://www.potatogenome.net) has been established with the primary objective of elucidating the complete sequence of the potato genome ( $840 \mathrm{Mb}$ ) by the end of 2008 . This initiative, which is based on the construction of a BAC-based physical map, is grounded in a previously constructed ultra-high density (UHD) genetic linkage map of the parents of a diploid $F_{1}$ potato population, comprising 10000 genetic markers [7] (http://potatodbase.dpw.wau.nl/UHDdata.html).

\section{Adopting biotechnology in potato breeding}

It can take up to 15 years to develop a single potato cultivar through traditional breeding [8]. For the majority of the genetic mapping studies to date, the goal has been to provide a basis for marker assisted selection (MAS) strategies in breeding, where selection is practised on genetic markers linked to genes conferring beneficial phenotypes. This can permit early and efficient selection for the traits of interest, allowing 'stacking' of genetically distinct components of the same trait and potentially shortening the breeding process by several years. Despite its potential, few instances of MAS in potato breeding have been reported. This is largely because of the outbreeding, tetraploid genetics of cultivated potato and because many traits of interest to potato breeders are truly polygenic in nature with a large environmental component. In this scenario, the efficacy of QTL mapping is much reduced, with the greatest difficulty being to develop markers that are diagnostic for (as opposed to just linked to) multiple small-effect QTLs. However, it is anticipated that this situation will be improved by the output of the aforementioned genomics-based studies, which will, in the longer term, allow the identification of many of the genes underlying the most important traits (e.g. carbohydrate metabolism). Instances where MAS is currently being used in potato breeding are largely confined to single dominant genes, or to large-effect QTL. An excellent illustration of this is the case of dominantly inherited disease resistance and large-effect QTLs for disease resistance, the majority of which have been found to be mediated by a single class of genes sharing conserved nucleotide-binding-site (NBS) and leucine-rich repeat (LRR) motifs (reviewed in [3]). On the basis of their map location, several NBS-LRR-type disease resistance genes have now been cloned and characterized to a level sufficient to offer real prospects for their MAS. Recently, Bernard Caromel et al. [9] showed the potential of MAS for the introgression of disease resistance genes in a potatobreeding scenario by demonstrating the effectiveness of this approach for 'stacking' two separate QTL for potato cyst nematode resistance into individual genotypes, which resulted in a more-robust resistance phenotype than would be obtained by the presence of a single QTL.

An alternative strategy for deploying resistance genes is through their direct introduction into potato breeding material using a transgenic approach. Since the first reports in 1986 [10,11], the successful nuclear integration of a heterologous gene(s) into the potato genome has been described for a range of starting tissues, including the Agrobacterium tumefaciens-mediated transformation of leaf tissue [12], tubers [13] and internodal segments [14], and direct gene transfer into leaf, tuber and internodes through particle bombardment [15]. The recent development of an efficient process of direct DNA uptake (in leaf explants) indicates that transgene expression levels equivalent to those mediated through the more commonly 
used Agrobacterium-based systems can be obtained with particle bombardment [16]. This is of particular significance for the transfer of multiple transgenes, which in turn could facilitate in manipulating the metabolic pathways of potato [16]. The transformation of the plastid genome of potato has also been demonstrated [17,18], which can offer high returns in protein yield. Though a prerequisite for establishing plant manufactured vaccine systems, its applicability is limited to relatively simple, aglycosylated proteins.

Although large genotype-dependent variation can be expected for both the regeneration and transformation efficiency of potato varieties through Agrobacteriumbased systems $[19,20]$, new tools and approaches for the production of transgenic plants are now providing a fresh perspective into how gene transfer can be achieved. For example, Wim Broothaerts et al. [21] have successfully engineered transgenic rice, Arabidopsis and tobacco using Rhizobium spp., Mesorhizobium loti and Sinorhizobium meliloti; a significant development in light of the complex patent issues associated with Agrobacterium-based systems [22]. In addition, Tony Conner and colleagues have identified sequences within the potato genome that can be used to construct novel transformation vectors (T. Conner, personal communication) composed of plantderived sequence, in contrast to using vectors of bacterial origin. This opens up the possibility of using an intragenic vector system to create non-transgenic GM lines.

For potato, the combination of map-based cloning with an Agrobacterium-based transgenic approach has permitted the characterization and introgression of genes from the wild species Solanum bulbocastanum (RB [23], Rpi-blb1 [24], Rpi-blb2 [25]) that confer strong resistance to Phytophthora infestans (Figure 2). Conversely, disease

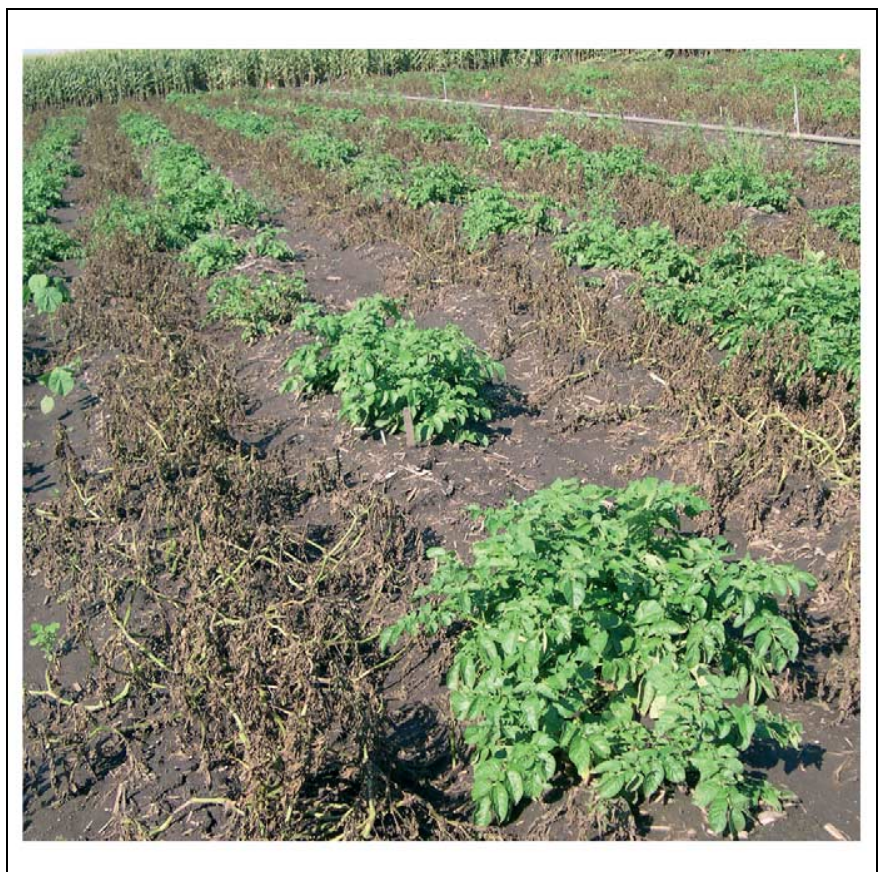

Figure 2. Field trial demonstrating the performance of GM potato (cv. Kathadin) transformed with the $R B$ gene next to border rows of the diseased control (cv. Norchip). Photograph taken 21 days post inoculation with Phytophthora infestans (US-8). Photograph courtesy of Dimitre S. Mollov and James M. Bradeen. resistance in potato can be achieved via the introduction of heterologous genes into the potato genome, for example: resistance to the Colorado beetle (Leptinotarsa decemlineata) through the constitutive expression of the $B t$ gene (which expresses Bacillus thuringiensis toxins) [26,27]; resistance to Verticillium dahliae by over expressing a Medicago sativa cysteine-rich defensin [28]; and resistance to Phytophthora erythroseptica and P. infestans [29] through accumulation of the cationic peptide temporin A. Resistance to $P$. infestans (and Alternaria solani) has also been reported through gene silencing [30] and by elevating levels of hydrogen peroxide, which also conferred resistance to the bacterial soft-rot pathogen Erwinia carotovora [31]. Although potato virus Y (PVY) and potato virus $\mathrm{X}(\mathrm{PVX})$ resistance has been achieved through expression of the heterologous potato leaf roll virus ORF4 gene [32], RNA silencing has also been used to engineer strong resistance to PVY [33].

\section{Alternative production systems}

Arguably, the most significant outcome arising from the technology-driven programmes of potato research has been the expansion of the use of potato into non-food applications. Modifying tuber starch content has been a goal for many years because of the commercial importance of processed starch as a food additive in, for example, high fructose syrup and various other technical processes [34]. Although the genetic complexity of tuber starch is evident by the identification of carbohydrate-metabolism-associated QTLs on the 12 chromosomes of potato (reviewed in [35]), significant milestones have been achieved through biotechnological approaches.

Such QTL mapping experiments, combined with the generation of a molecular-function map for carbohydrate metabolism [36], has offered researchers the potential to adopt an endogenous candidate gene approach to address such production issues as cold-sweetening in processed tubers [37], be that through a transgenic or a MAS approach (reviewed in [38]). For example, modification of the plastidic ATP and/or ADP transporter activity increased the amylose content of starch to 27\% [39]. Additionally, further genetic manipulation has achieved a $60 \%$ increase in starch levels compared with wild-type plants [34]. A much-desired property for starch is freezethaw stability, which is typically achieved through chemical substitution. Through the antisense inhibition of three starch synthase genes, starch has been generated that maintains its stability through five freeze-thaw cycles [40]. Therefore, as the ability to modify potato starch via genetic modification is realized, it provides an opportunity to use native starch to achieve specific, valuable functionalities [41] - the commercial relevance of which is reflected in the number of notifications (25 to date) that have been made for field-testing GM potato with altered starch profiles (http://gmoinfo.jrc.it/).

The ability to achieve high synthesis scales at low manufacturing costs has led to plants being used as bioreactors for the production of therapeutic molecules, and to plants emerging as a competitor to established industrial processes [42-44]. The suitability of potato for therapeutic molecule production has been demonstrated 
with the crop being used in three of the six clinical trials completed to date [44], one of which was the first to demonstrate human immunogenicity to an in plantaproduced vaccine candidate following the administration of tubers expressing a capsid protein of the Norwalk virus (causative organism of epidemic acute gastroenteritis) [45].

The potential of using an edible, plant-based vaccination system for protection against HIV-1 infection has been demonstrated using transgenic potato expressing the HIV-1 envelope glycoprotein gp120 [46]. In addition, the potential of using a potato-based vaccine in a global immunization programme against hepatitis B (global mortality rate of 1 million cases per year) has been illustrated, with $57 \%$ of individuals tested developing an immunogenic response following the ingestion of hepatitis B surface antigen (HBsAg)-expressing potato. Significantly this was recorded with a non-replicating vaccine that was delivered orally in the absence of an adjuvant [47].

Analysis of transgenic potato expressing the full-length spike protein of infectious bronchitis virus has highlighted its potential in a veterinary context as a vaccine delivery system in chickens [48]. An immunogenic response has been induced in mice fed with transgenic potato expressing the VP1 structural protein of the foot and mouth disease virus [49]. Furthermore, expression of the neutralizing epitope of swine porcine epidemic diarrhoea virus (PEDV) has led to the accumulation of the PEDV protein to levels of up to $0.1 \%$ of total soluble tuber protein [50].

The genetic modification of potato has also been used to improve the functional properties of tuber-derived flour through the over-expression of the wheat low-molecularweight glutenin gene [51]. Eva Farre et al. have adopted a transgenic approach to reduce pre-sprouting dormancy by six to seven weeks [52] and transgenic potato plants have been modified to accumulate high levels $(1.1 \%$ of dry weight) of a cyanophycin-like polymer, opening the way for the future production of biodegradable plastics using a plant-based production system [53].

\section{The GM issue}

In $2005,8.5$ million farmers across 21 countries voluntarily cultivated $>90$ million hectares of GM crops (http:// www.isaaa.org/kc/bin/briefs34/pr/index.htm). Yet, consumer apprehension towards GM technology still exists and centres on the public's desire for unbiased information on the perceived risks associated with the technology. So, focussing solely on GM potato, what are these perceived risks and have they or can they be addressed? Generic risks described for GM potato (and which typically are raised against all GM crops) relate to:

- The potential for transgene gene flow into adjacent non-GM populations.

- The potential allerginicity of the transgene postconsumption.

- The development of a super-pest that could render the transgenic phenotype obsolete.

The application of a novel, quantitative gene flow index to potato calculates the propensity for transgene escape through pollen and/or seed-mediated gene flow as a score of 6 out of a maximum of 27 [54]. This low value was attained because of the high degree of male sterility in many varieties and a low transmission distance for pollen dispersal in the remaining male fertile material $[55,56]$. In addition, for crop-to-wild relative hybridization within Europe, potato is considered to be genetically contained owing to the lack of sexual compatibility between commercial potato varieties and the two related wild species Solanum nigrum and Solanum dulcamara. Combined with the clonal nature of the crop, this serves to minimize the potential for gene flow to emerging groundkeepers (volunteer potatoes arising from tubers left in the soil) post-harvest [57], which in turn can be negated through appropriate crop management.

In contrast to the issue of gene flow, which is dependent upon the biology of the potato plant (be it GM or non-GM), the allergenic potential of a GM potato crop is dependent upon the product of the transgene. As such, each GM potato line must be considered individually so that results that emanate from the risk assessment of one GM potato line are not used to brand all GM potato material generically. Such a scenario occurred in 1998, when studies conducted by Arpad Pustzai indicated that rats fed a diet of potato engineered to produce the snowdrop lectin GNA suffered from stunted growth and deficient immune systems. Although the research methodology was the focus of critical discussion within the scientific community (discussed in [1]), the general public were left with the impression that all GM potato lines had the potential to cause physical harm.

Genetic modifications in potato carbohydrate metabolism and/or capacity to resist disease are likely to result in changes to the profile of plant defence compounds in the tuber [58]. However, it is crucial to determine whether GM potato cultivated under field conditions will pose a risk to human and/or animal health. Recent work by Gareth Catchpole and colleagues [59] indicated that the metabolome of field-grown GM and conventional potatoes were substantially equivalent, apart from the targeted changes in the GM populations. The application of high-resolution metabolic and/or proteomic profiling [60-62] in this manner is an important step for determining substantial equivalence but, notably, is only one part of a multidisciplinary risk assessment that is required before GMderived material can enter the food chain. This exhaustive approach might seem superfluous given that potato tubers are considered to be mildly toxic [58], but adopting an overtly precautionary approach is both sensible and necessary in light of consumer sensitivities to the GM issue.

By contrast, the durability of GM crops must be considered in the context of what occurs in traditional cropping systems. As increasingly efficient conventional crop systems are commercialized, pests evolve to evade the novel control measures, thereby ensuring their survival (e.g. fungicide resistance in Mycosphaerella graminicola [63]). Significantly, pest evolution will occur irrespective of whether the novel plant phenotype is developed through conventional plant breeding or genetic modification. 


\section{Box 1. NewLeaf ${ }^{\mathrm{TM}}$ potato}

Developed by the Monsanto subsidiary NatureMark (http://www. naturemark.com), NewLeaf ${ }^{\mathrm{TM}}$ was engineered to resist the Colorado beetle (Leptinotarsa decemlineata) and was made commercially available in 1995. Primarily grown in the American pacific northwest, NewLeaf ${ }^{\mathrm{TM}}$ was followed by NewLeaf Plus ${ }^{\mathrm{TM}}$ and NewLeaf $\mathrm{Y}^{\mathrm{TM}}$, which were resistant to potato leaf roll virus (PLRV) and potato virus $Y$ (PVY), respectively [69]. Following decisions by the major food processors (e.g. McDonalds, Burger King, Frito-Lay and Proctor \& Gamble) [69]) to prohibit the inclusion of GM potatoes in their products because of activist pressure, NewLeaf ${ }^{\mathrm{TM}}$ growers had no choice but to revert to conventional germplasm and the subsequent reintroduction of large-scale applications of the primary insecticides (e.g. pyrethrin, organo-chlorines and carbamates) to which target insects have now developed high levels of resistance (http://www. oznet.ksu.edu/dp_hfrr/extensn/problems/colpotat.htm).

Consequently, strategies to maintain the durability of the novel crop (e.g. gene stacking and establishment of insect refuges) are applicable to both GM and non-GM crops.

For $B t$ potato (as it is for all $B t$ crops), the cultivation of non- $B t$ refuges adjacent to the $B t$ crop is essential to reduce the evolutionary pressure placed upon the target pest through the cultivation of the $B t$ crop. By growing susceptible plants to attract the target insect (e.g. Colorado beetle) the rate of increase in resistance within the beetle is delayed because the number of susceptible beetles within the population is maintained on the refuges (explained by [64]), thereby prolonging the efficacy of the crop. Gene stacking is equally important in maintaining the durability of a novel phenotype and has been adopted for the generation of a GM potato line (containing the Rpiblb1 and Rpi-blb2 genes from S. bulbocastanum [24,25]) currently being tested for resistance to $P$. infestans (http://gmoinfo.jrc.it/). Because the commercialization of this material could have a significant impact on net grower income [65] (€417 million annually for Europe alone [66]), it is not surprising that field trials are being conducted.

Although there are valid economic and environmental reasons for commercializing such a crop [66], to ensure that the events linked to the cultivation of $B t$ potato in 2001 (Box 1) are not repeated, it is important that the regulatory agencies adopt a proactive approach to address consumer apprehension. Information sources such as GMO-Compass (http://www.gmo-compass.org) and the establishment of the European Food Safety Authority (EFSA) (http://www.efsa.eu.int), which was set up to reestablish consumer confidence in the European food network, will go someway to achieving this objective. Although an anticipated benefit from $P$. infestans-resistant GM potato could be a reduced commodity cost owing to increased yields, it is still a challenge to elucidate the direct benefits such a cultivar could offer consumers and/ or stakeholders in those countries that do not experience food shortages or micronutrient deficiency. This contrasts with persons dependent upon agriculture for their survival, where specific GM potato lines tailored to address local abiotic and/or biotic stresses could present an alternative to existing systems [67].

\section{Looking ahead}

From the time of its introduction into Europe from South America approximately 400 years ago, potato has experienced continuous modification via man's unconscious and conscious action. This has resulted in its development from a poorly performing botanical curio into the fourth largest cultivated food crop in the world. Over the past 20 years, the application of biotechnology approaches has begun to unravel the intricacies of the potato genome and proteome. Consequently, researchers are capitalizing on the availability of novel data-sets to address fundamental biological questions. Allied with emerging high-throughput techniques and the excellent germplasm resources currently available (Box 2), the sum of large-scale genomics-based potato research should have a radical impact on our ability to link genes with traits in potato over the next decade.

Nonetheless, as scientists forge ahead in deciphering the workings of such major crops as potato, the general public remains apprehensive about what is being done. As a result, an emotive debate centred on the perceived risks of various tools of biotechnology (e.g. genetic modification) has prevailed. Unless the consumer can experience the direct benefits of the science, any perceived risk from a GM crop will outweigh the benefits [68], which is most relevant to the present European Union (EU) where objection to GM crops is the most vociferous. However, this could change in the near future with the modification of potato to produce industrial, pharmaceutical and veterinarian products. Indeed, the recent increase in the number of notifications submitted for Class B release of GM potato lines within the EU member states (http:// gmoinfo.jrc.it/) is an early indicator to the public as to the expanding remit of potato, which we predict will further

\section{Box 2. Importance of maintaining genetic resources}

The preservation and study of wild potato germplasm is crucial to the development of potato, be that through a molecular genetics $[23,24,70-73]$ or traditional breeding approach (reviewed in [35]). Indeed, the importance associated with maintaining biodiversity has been underpinned through the United Nation's Convention on Biological Diversity (http://www.biodiv.org/convention/articles.asp).

The genus Solanum comprises $>1000$ species, with the tuberbearing section Petota comprising $\sim 225$ species, including the tetraploid Solanum tuberosum subsp. tuberosum and subsp. andigena (the andigena potato) [74]. Although worldwide potato production is dominated by the smooth tubers of $S$. tuberosum, local communities in the Andean region cultivate a range of species and primitive cultivars from the Solanum brevicaule species complex that show a wide diversity of tuber types (http://www.cipotato.org/). Wild potato species inhabit a range of different mountain habitats and have therefore had to adapt to a wide range of biotic and abiotic stresses. This is in contrast to their cultivated relatives who, because of their relatively narrow eco-geographical origin, are adapted to relatively few environments and diseases [35]. Consequently, subsp. andigena and other semi-wild mountain taxa that show diverse disease and frost resistance qualities, among others, remain a major source of germplasm for commercial breeding. To maximize the utility of these resources, germplasm collections have been established (for a comprehensive list see http://www.cgn.wagenin gen-ur.nl/pgr/ collections/crops/potato/genbanks.htm). These gene banks represent a precious resource that continues to benefit current breeding programmes (http://www.cipotato.org/) and applied and strategic research agendas $[23,25]$. 
accelerate in the years ahead as the existing research base continues to expand.

\section{Acknowledgements}

We extend our gratitude to Susanne Ivers for collating the WHO FAO data on global potato production. Funding in support of E.M., C.P. and D.M. was provided through Ireland's National Development Fund.

\section{References}

1 Fedoroff, N.V. and Brown, N.M. (2005) Mendel in the Kitchen. A Scientist's View of Genetically Modified Foods, Joseph Henry Press

2 FAOSTAT (2005) Food and Agricultural Organization of the United Nations Statistical Database, (http://faostat.fao.org)

3 Gebhardt, C. and Valkonen, J.P.T. (2001) Organization of genes controlling disease resistance in potato. Annu. Rev. Phytopathol. 39, 79-102

4 Mathews, H. et al. (2003) Activation tagging in tomato identifies a transcriptional regulator of anthocyanin biosynthesis, modification, and transport. Plant Cell 15, 1689-1703

5 Weigel, D. et al. (2000) Activation tagging in Arabidopsis. Plant Physiol. 122, 1003-1014

6 Faivré-Rampant, O. et al. (2004) Potato Virus X-induced gene silencing in leaves and tubers of potato. Plant Physiol. 134, 1308-1316

7 Isidore, E. et al. (2003) Toward a marker-dense meiotic map of the potato genome: lessons from linkage group I. Genetics 165, 2107-2116

8 Bradshaw, J.E. and Mackay, G.R. (1994) Breeding strategies for clonally propagated potatoes. In Potato Genetics (Bradshaw, J.E. and Mackay, G.R., eds), pp. 3-42, CAB International

9 Caromel, B. et al. (2005) Resistance quantitative trait loci originating from Solanum sparsipilum act independently on the sex ratio of Globodera pallida and together for developing a necrotic reaction. Mol. Plant Microbe Interact. 18, 1186-1194

10 An, G. et al. (1986) Transformation of tobacco, tomato, potato and Arabidopsis thaliana using a binar Ti vector system. Plant Physiol. 81, 301-305

11 Shahin, E.A. and Simpson, R.B. (1986) Gene transfer system for potato. HortScience 21, 1199-1201

12 De Block, M. (1988) Genotype-independent leaf disc transformation of potato (Solanum tuberosum) using Agrobacterium tumefaciens. Theor. Appl. Genet. 76, 767-774

13 Ishida, B. et al. (1989) The use of in-vitro grown micro-tuber discs in Agrobacterium tumefaciens mediated transformation of Russet Burbank and Lemhi Tusset potatoes. Plant Cell Rep. 8, 325-327

14 Newell, C.A. et al. (1991) Agrobacterium-mediated transformation of Solanum tuberosum L. cv. 'Russet Burbank'. Plant Cell Rep. 10, 30-34

15 Romano, A. et al. (2001) Transformation of potato (Solanum tuberosum) using particle bombardment. Plant Cell Rep. 20, 198-204

16 Craig, W. et al. (2005) Direct gene transfer in potato: a comparison of particle bombardment of leaf explants and PEG-mediated transformation of protoplasts. Plant Cell Rep. 24, 603-611

17 Sidorov, V.A. et al. (1999) Stable chloroplast transformation in potato: use of green fluorescent protein as a plastid marker. Plant J. 19, 209-216

18 Nguyen, T.T. et al. (2005) Generation of homoplasmic plastid transformants of a commercial potato cultivar (Solanum tuberosum L.). Plant Sci. 168, 1495-1500

19 Dale, P.J. and Hampson, K.K. (1995) An assessment of morphogenic and transformation efficiency in a range of varieties of potato (Solanum tuberosum L.). Euphytica 85, 101-108

20 Herres, P. et al. (2002) Transformation of a large number of potato varieties: genotype-dependent variation in efficiency and somaclonal variability. Euphytica $124,13-22$

21 Broothaerts, W. et al. (2005) Gene transfer to plants by diverse species of bacteria. Nature 433, 629-632

22 Chung, S-M. et al. (2006) Agrobacterium is not alone: gene transfer to plants by viruses and other bacteria. Trends Plant Sci. 11, 1-4

23 Song, J. et al. (2003) Gene RB cloned from Solanum bulbocastanum confers broad spectrum resistance to potato late blight. Proc. Natl. Acad. Sci. U. S. A. 100, 9128-9133
24 van der Vossen, E. et al. (2003) An ancient $R$ gene from the wild potato species Solanum bulbocastanum confers broad-spectrum resistance to Phytophthora infestans in cultivated potato and tomato. Plant J. 36, 867-882

25 van der Vossen, E. et al. (2005) The Rpi-blb2 gene from Solanum bulbocastanum is an Mi-1 homolog conferring broad-spectrum late blight resistance in potato. Plant J. 44, 208-222

26 Perlak, F. et al. (1993) Genetically improved potatoes: protection from damage by Colorado potato beetles. Plant Mol. Biol. 22, 313-321

27 Adang, M.J. et al. (1993) The reconstruction and expression of a Bacillus thuringiensis cryIIIA gene in protoplasts and potato plants. Plant Mol. Biol. 21, 1131-1145

28 Gao, A-G. et al. (2000) Fungal pathogen protection in potato by expression of a plant defensin peptide. Nat. Biotechnol. 18, 1307-1310

29 Osusky, M. et al. (2004) Transgenic potatoes expressing a novel cationic peptide are resistant to late blight and pink rot. Transgenic Res. 13, 181-190

30 Conrath, U. et al. (2003) Enhanced resistance to Phytophthora infestans and Alternaria solani in leaves and tubers, respectively, of potato plants with decreased activity of the plastidic ATP/ADP transporter. Planta 217, 75-83

$31 \mathrm{Wu}$, G. et al. (1995) Disease resistance conferred by expression of a gene encoding $\mathrm{H}_{2} \mathrm{O}_{2}$-generating glucose oxidase in transgenic potato plants. Plant Cell 7, 1357-1368

32 Tacke, E. et al. (1996) Genetic engineering of potato for broadspectrum protection against virus infection. Nat. Biotechnol. 14, 1597-1601

33 Missiou, A. et al. (2004) Generation of transgenic potato plants highly resistant to potato virus Y (PVY) through RNA silencing. Mol. Breed. $14,185-197$

34 Regierer, B. et al. (2002) Starch content and yield increase as a result of altering adenylate pools in transgenic plants. Nat. Biotechnol. 20, $1256-1260$

35 Milbourne, D. et al. Potato. In Genome Mapping \& Molecular Breeding in Plants (Vol. 3) (Kole, C., ed.), Springer Publishers (in press)

36 Chen, X. et al. (2001) A potato molecular-function map for carbohydrate metabolism and transport. Theor. Appl. Genet. 102, 284-295

37 Menendez, C.M. et al. (2002) Cold sweetening in diploid potato: mapping quantitative trait loci and candidate genes. Genetics 162, 1423-1434

38 Dale, M.F.B. and Bradshaw, J.E. (2003) Progress in improving processing attributes in potato. Trends Plant Sci. 8, 310-312

39 Tjaden, J. et al. (1998) Altered plastidic ATP/ADP-transporter activity influences potato (Solanum tuberosum L.) tuber morphology, yield and composition of tuber starch. Plant J. 16, 531-540

40 Jobling, S.A. et al. (2002) Production of a freeze-thaw-stable potato starch by antisense inhibition of three starch synthase gene. Nat. Biotechnol. 20, 295-299

41 Blennow, A. et al. (2005) Structure function relationships of transgenic starches with engineered phosphate substitution and starch branching. Int. J. Biol. Macromol. 36, 159-168

$42 \mathrm{Ma}$, J.K-C. et al. (2005) Molecular farming for new drugs and vaccines. EMBO Rep. 6, 593-599

43 Ma, J.K-C. et al. (2003) The production of recombinant pharmaceutical proteins in plants. Nat. Rev. Genet. 4, 794-805

44 Twyman, R.M. et al. (2005) Transgenic plants in the biopharmaceutical market. Expert Opin. Emerg. Drugs 10, 185-218

45 Tacket, C.O. et al. (1998) Immunogenicity in humans of a recombinant bacterial-antigen delivered in transgenic potato. Nat. Med. 4, 607-609

46 Kim, T.G. et al. (2004) HIV-1 gp120 V3 cholera toxin B subunit fusion gene expression in transgenic potato. Protein Expr. Purif. 37, 196-202

47 Thanavala, Y. et al. (2005) Immunogenicity in humans of an edible vaccine for hepatitis B. Proc. Natl. Acad. Sci. U. S. A. 102, 3378-3382

48 Zhou, J.Y. et al. (2004) Generation of the transgenic potato expressing full-length spike protein of infectious bronchitis virus. J. Biotechnol. 111, 121-130

49 Carrillo, C. et al. (2001) Induction of a virus-specific antibody response to foot and mouth disease virus using the structural protein Vp1 expressed in transgenic potato plants. Viral Immunol. 14, 49-57

$50 \mathrm{Kim}, \mathrm{Y}$-S. et al. (2005) Expression of neutralizing epitope of porcine epidemic diarrhoea virus in potato plants. Plant Cell Tissue Organ Cult. $82,125-130$ 
51 Benmoussa, M. et al. (2004) Potato flour viscosity improvement is associated with the expression of a wheat LMW-glutenin gene. Biotechnol. Bioeng. 87, 495-500

52 Farre, E.M. et al. (2001) Acceleration of potato tuber sprouting by the expression of a bacterial pyrophosphate. Nat. Biotechnol. 19, 268-272

53 Neumann, K. et al. (2005) Production of cyanophycin, a suitable source for the biodegradable polymer polyaspartate, in transgenic plants. Plant Biotechnol. J. 3, 249-258

54 Flannery, M.L. et al. (2005) Employing a composite gene-flow index to numerically quantify a crop's potential for gene flow: an Irish perspective. Environ. Biosafety Res. 4, 29-43

55 Tynan, J.L. et al. (1990) Low frequency of pollen dispersal from a field trial of transgenic potatoes. J. Genet. Breed. 44, 303-306

56 Conner, A. and Dale, P.J. (1996) Reconsideration of pollen dispersal data from field trials of transgenic potatoes. Theor. Appl. Genet. 92, 505-508

57 Eastham, K. and Sweet, J. (2002) Genetically modified organisms (GMOs): the significance of gene flow through pollen transfer. European Environment Agency, Environmental Issue Report No. 28,75

58 Matthews, D. et al. (2005) Toxic secondary metabolite production in genetically modified potatoes in response to stress. J. Agric. Food Chem. 53, 7766-7776

59 Catchpole, G.S. et al. (2005) Hierarchical metabolomics demonstrates substantial compositional similarity between genetically modified and conventional potato crops. Proc. Natl. Acad. Sci. U. S. A. 102, 14458-14462

60 Roessner, U. et al. (2001) Metabolic profiling allows comprehensive phenotyping of genetically or environmentally modified plant systems. Plant Cell 13, 11-29

61 Roessner, U. et al. (2001) High-resolution metabolic phenotyping of genetically and environmentally diverse potato tuber systems. Identification of phenocopies. Plant Physiol. 127, 749-764

62 Lehesranta, S.J. et al. (2005) Comparison of tuber proteomes of potato varieties, landraces, and genetically modified lines. Plant Physiol. 138, 1690-1699
63 Fraaije, B.A. et al. (2005) The role of ascospores in further spread of QoI-resistant cytochrome b alleles (G143A) in field populations of Mycosphaerella graminicola. Phytopathology 95, 933-941

64 Cohen, M.B. et al. (2000) Bt rice: practical steps to sustainable use. International Rice Research Notes 25, 4-10

65 Flannery, M-L. et al. (2005) An economic cost-benefit analysis of GM crop cultivation: an Irish case study. J. Agrobiotechnology Manag. Econ. 7, 1

66 Gianessi, L.P. et al. (2003) Plant Biotechnology: Potential Impact for Improving Pest Management in European Agriculture. A Summary of Three Case Studies, National Centre for Food and Agricultural Policy, (http://www.ncfap.org)

67 Atkinson, H.J. et al. (2001) The case for genetically modified crops with a poverty focus. Trends Biotechnol. 19, 91-96

68 Maliga, P. and Graham, I. (2004) Molecular farming and metabolic engineering promise a new generation of high-tech crops. Curr. Opin. Plant Biol. 7, 149-151

69 Kaniewski, W.K. and Thomas, P.E. (2004) The Potato Story. J. Agrobiotechnology Manag. Econ. 7, 41-46

70 Tek, A.L. et al. (2004) Transfer of tuber soft rot and early blight resistances from Solanum brevidens into cultivated potato. Theor. Appl. Genet. 109, 249-254

71 Park, T.H. et al. (2005) The late blight resistance locus Rpi-blb3 from Solanum bulbocastanum belongs to a major late blight $\mathrm{R}$ gene cluster on chromosome 4 of potato. Mol. Plant Microbe Interact. 18, 722-729

72 Armstrong, M.R. et al. (2005) An ancestral oomycete locus contains late blight avirulence gene Avr3a, encoding a protein that is recognized in the host cytoplasm. Proc. Natl. Acad. Sci. U. S. A. 102, 7766-7771

73 Smilde, W.D. et al. (2005) Solanum mochiquense chromosome IX carries a novel late blight resistance gene Rpi-moc1. Theor. Appl. Genet. 110, 252-258

74 Volkov, R.A. et al. (2003) Molecular evolution of rDNA external transcribed spacer and phylogeny of sect. Petota (genus Solanum). Mol. Phylogenet. Evol. 29, 187-202

Plant Science meetings sponsored by Trends in Plant Science

\author{
Haploids in Higher Plants III \\ 12-15 February 2006 \\ Vienna, Austria \\ http://www.univie.ac.at/gem/conference/haploids/ \\ The Second Symposium on Plant Neurobiology \\ 22-27 May 2006 \\ Beijing, China \\ http://plantneurobiology.ibcas.ac.cn/index.htm
}

2006 FASEB Summer Research Conference:

'Mechanisms in Plant Development'

5-9 August 2006

Vermont Academy, Saxtons River, VT, USA

http://src.faseb.org/preliminary.htm 